\title{
Neuroaesthetics: Maladies and Remedies
}

\author{
Michael Kubovy ${ }^{\dagger}$
}

\begin{abstract}
Some neuroaestheticians have adopted a strongly reductionistic view of the arts and sought to supplant scholarship about the arts with an understanding of their evolutionary and neuropsychological underpinnings. I use the work of several neuroaestheticians to provide examples of four problematic tendencies that beset this approach: (1) assume that a domain-general system encodes the affective value of works of art; (2) oversimplify or disregard art history and scholarship about the arts; (3) apply laboratory findings to explain unique works of art, and (4) use widespread preferences to account for works of art. I then diagnose the ailment underlying these tendencies: the denial of autonomous standing to the production and interpretation of the arts, and suggest remedies. I end with an example of research that shows how neuroscientific research can successfully addresses an important and long-standing aesthetic question.
\end{abstract}

Keywords: reductionism, the two-culture phenomenon, domain-general code for value, multiattribute decision making, the remembering self, slow looking, savanna hypothesis, aesthetics from below

In 1959 (Snow, 2013) lamented the failure of non-scientists to keep abreast of the scientific revolution of the 20th century:

Between [literary intellectuals and scientists there is] a gulf of mutual incomprehension - sometimes ... hostility and dislike, but most of all lack of understanding. They have a curious distorted image of each other. Their attitudes are so different that, even on the level of emotion, they can't find much common ground. (pp. 4-5)

As a result - he says - even when poets do use scientific expressions, they end up "getting them wrong" (pp. 17-18). In other words, non-scientists need to get their act together and learn some science, or else the gulf between the two cultures will never be bridged. But the burden of building a bridge between the two is on the non-scientists.

Some three decades later, the lament of scientists grew louder and more bitter. Not only did they think that scholars in the humanities are ignorant of science, they also thought that

\footnotetext{
${ }^{\dagger}$ Email: kubovy@virginia.edu I dedicate this article to the memory of Marcel M. Franciscono, art historian and friend, who would have done much to improve this article. I thank J. T, Cargile, W. R. Epstein, S. Gepshtein, A. M. Glenberg, D. R. Proffitt, J. Shatin, and J. D. Summers, for their helpful comments.
} 
even on their home turf they can't tell good scholarship from bad. To make this point, the theoretical physicist Alan Sokal (1996a b) submitted a meaningless article - a pastiche of postmodernist verbiage - to a prestigious journal, Social Text ${ }^{1}$ The journal accepted the article and published it, eliciting much glee and gloating (Scott, 1996, Sokal and Bricmont, 1998).

There is also resistance on the humanist side of the two-culture chasm. It is not unusual to find scholars deprecating what they consider to be the scientific method, often under the banner of antipositivism (Giedymin, 1975). Two influential examples make this point.

The first comes from Foucault. For him, to understand knowledge you must also understand the nature of power. According to Gutting and Oksala (2018), Foucault thinks that

... the relation of power and knowledge is far closer than in the familiar Baconian engineering model, for which "knowledge is power" means that knowledge is an instrument of power, although the two exist quite independently. [For Foucault] ... at least for the study of human beings, the goals of power and the goals of knowledge cannot be separated: in knowing we control and in controlling we know. (p. 16)

[He] question[s] the naturalistic explanatory framework that understands human nature - uncovered by science - as the basis for ... complex areas of behavior ... (p. 19)

The second comes from Geertz's (1973) view of ethnographic research:

The whole point of a semiotic approach to culture is ... to aid us in gaining access to the conceptual world in which our subjects live so that we can, in some extended sense of the term, converse with them. (p. 320)

Geertz wants cultural anthropologists to come as close as possible to a first-person perspective on a culture. As a result, he recommends an approach that is anathema to scientists:

Rather than following a rising curve of cumulative findings, cultural analysis breaks up into a disconnected yet coherent sequence of bolder and bolder sorties. Studies do build on other studies, not in the sense that they take up where the others leave off, but in the sense that, better informed and better conceptualized, they plunge more deeply into the same things. ... A study is an advance if it is more incisive — whatever that may mean — than those that preceded it; but it less stands on their shoulders than, challenged and challenging, runs by their side. (p. 320)

Such was the backdrop — roughly two decades ago — against which Ramachandran and Hirstein (1999), Solso (2003), Zaidel (2005), and Zeki (1999a b), to name a few, created the field of neuroaesthetics. They evince appreciation for the arts (often through ravishing color plates), and for their importance in human life. At the same time they are unremittingly

${ }^{1}$ Thoughtfully analyzed by Guillory [2002). 
reductionistic. They take it as given that explanatory power rests with neuroscience. Thus they imply - if scholars in the humanities were to understand the value of neuroscience to their studies, they would have to cross the bridge toward the neuroscientists. The neuroscientists, believing that they know the scientific method, and that they are good exponents of it, see no reason to budge from their side of the two-cultures chasm.

I caution against such a view of the relation between neuroscience and the arts. First, I observe that neuroscientists have made unjustified and sweeping claims about the neural foundations of aesthetics. Second, I argue for autonomy of the arts from neuroscience.

\section{Four maladies}

\section{Malady 1: Assume a domain-general code}

Skov and Nadal (2018) recommend that we abandon the commonly held idea "that cognitive or neural processes associated with experiences of art are art-specific" (p. 699). Instead

a ... neural network ... represents the reward value of ... objects, situations, or events as a single neural currency ... whether a drink tastes good, whether something smells nice, ... [as well as] the affective value of a Mark Rothko painting, of Stockhausen's serial compositions, or of any other work of art.

This bold idea of a domain-general neural code for value, also known as a single or common currency (Levy and Glimcher, 2012), is widely accepted in neuroeconomics (Huettel, 2014, Landreth and Bickle, 2008, Mannella et al. 2013, Reyna and Huettel, 2014). Unfortunately, it flies in the face of behavioral evidence ${ }^{2}$

\section{Evidence again a domain-general code}

An argument (attributed to L. J. Savage: Luce and Suppes, 1965, p. 334) goes like this. Imagine you have been given a gift of a vacation week next September, and you are even given a choice among three packages.: Paris, $P$, Rome, $R$, or Rome plus a voucher for a drink, $R+$. Since you would surely prefer not to pay for the drink, choosing $R+$ over $R$ is easy. Now suppose you are equally drawn to $P$ and $R$; this is a hard choice.

But what about the choice between $P$ and $R+$ ? The single currency idea implies that sweetening the Rome trip with a voucher should suffice to make it far more appealing than the trip to Paris. Intuition shows that this is false. The reason I have trouble choosing between Paris and Rome is not their indistinguishability, but rather the difficulty I have comparing of what I would like to do once I got there. Next September in Paris, I would be eager to see the Francis Bacon exhibit at the Pompidou museum, whereas in Rome I would love to participate in the Taste of Roma food festival. (This thought experiment is supported by experimental evidence obtained by Tversky and Shafir, 1992.)

\footnotetext{
${ }^{2}$ I am not alone in raising such doubts: Fumagalli 2013) has marshaled other arguments against the common currency view.
} 
Indeed, most decisions faced by humans (Tversky, 1972) and animals (such as bees: Tan et al. 2015) cannot be simply ordered, because the alternatives vary on several attributes. There is indeed an entire discipline devoted to this topic: multiattribute decision making $\mathrm{Xu}$. 2015), which deals with decisions involving multiple inputs. For example, social workers must make a recommendation to a court about removing a child from its home. This is a difficult decision, because they must weigh multiple attributes of the child's environment - economic stresses, the relationship between the parents and between them and the child, and so on.

\section{Perhaps a domain-general code does not extend to complex choices}

So, how to resolve the conflict between the consensus among neuroeconomists about the unidimensionality of value and the behavioral evidence against it?

Accept that a domain-general code may apply to sensory stimuli. First, we could reduce the scope of this unidimensionality claim to a narrower set of objects. After all, the rewards studied in the neuroeconomics literature are far simpler than those involved in choices of vacations or engagement with works of art. The simplicity of the rewards studied is immediately apparent in the following typical study study that purports to support the idea of a common code (Kahnt, 2018):

To test for a common value code ..., we used a Pavlovian learning task with two ... equally pleasant food odors (e.g. chocolate cake and pizza) ....... we constructed a high and low value version of each odor, resulting in a ... reward value $\times$ reward identity [design] $\ldots$. The ... odors served as unconditioned stimuli (US) and were associated with visual conditioned stimuli (CS ... ). Subjects were scanned while observing the pairings between CS and US. To test for a general value code, we trained a classifier on activity patterns evoked by CS predicting high vs low value versions of one food odor (e.g. chocolate cake), and tested the classifier on activity patterns evoked by CS predicting high vs low value versions of the second food odor (e.g., pizza). This cross-decoding of associative value was only possible in the vmPFC [ventromedial prefrontal cortex], suggesting that this region represents the value of different expected rewards on an identity-general value scale. (p. 329)

For the sake of argument, I will accept this study as evidence for unidimensionality of odor preferences. And yet one thing is clear: the study gives us no warrant to generalize the assertion of unidimensionality to vacations or works of art.

Recognize that works of art are not mere sensory stimuli. Second, I suggest that the preferences for vacations or works of art involve different psychological processes than do preferences for sensory stimuli. I can imagine readers sympathetic with Skov and Nadal s view, expecting me to give an argument that will hamper "a naturalized view of the mind." Far from it. Instead, I'd like to argue that Skov and Nadal have fallen into a category-mistake (Ryle, 2009 , p. 6). They imply that vacations or works of art trigger mental events belonging to 
the category of experienced moments. But this is the wrong category. We do not seek out vacations or works of art just for their moment-to-moment value but also (and perhaps mainly) for their capacity to engender episodes worth remembering, an entirely different category of mental event.

The distinction between these categories of experience comes from Kahneman and Riis (2005). They invite us to consider two different aspects of a person: the experiencing self and the remembering self.

An individual's life could be described ... as a string of moments. ... What happens to these moments? ... they simply disappear. ... When we are asked 'how good was the vacation,' it is not an experiencing self that answers, but a remembering and evaluating self, the self that keeps score and maintains records. Unlike the experiencing self, the remembering self is relatively stable and permanent. It is a basic fact of the human condition that memories are what we get to keep from our experience, and the only perspective that we can adopt as we think about our lives is therefore that of the remembering self. (pp. 285-286)

If we accept this view of the kind of reward we get from a vacation or work of art, we will not lump all pleasurable experiences into one category. We could then restrict the application of the notion of common currency to experienced moments.

And why should we not treat the perception of a work of art as a "moment"? To be sure some visitors to museums devote as little time to a Rothko painting as it takes to decide that something smells nice. But they are short-changing themselves. As Perkins (1994) points out, art must be "thought through" (p. 18), which "means slowing looking down" (p. 36) 3 Art-historian James Elkins (2001) puts it thus:

These days a visit to the museum is an opportunity to learn something, and take a little sip of pleasure here and there. ... That need not be so. Paintings repay the attention they are given .... the more you look, the more you feel. (Preface)

Thus Skov and Nadal are wrong on two counts: First, even if the magnitude of some kinds of rewards can be located on a single scale, this does not mean that preferences for works of art can be arranged on a single scale of value. Second, although works of art can be treated as rewards, aesthetic experiences should be treated as extended life-episodes rather than as momentary experiences.

\section{Malady 2: Oversimplify art history}

Nobel laureate Eric Kandel (2016), in his Reductionism in art and brain science: Bridging the two cultures, lays out the following thesis:

Much as a brain scientist can use reductionism to focus on very simple cases of learning and memory and to delineate the process of visual perception, so an artist

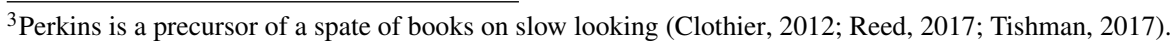


can use reductionism to focus on form, line, color, or light. In its most holistic form, reductionism allows an artist to move from figuration to abstraction, the absence of figuration. (p. 61)

The rest of his book consists of two sets of interleaved chapters, each written for a general audience. One set contains an elementary account of cognitive neuroscience; the other, a conventional narrative history of abstraction in art.

Unfortunately, Kandel's claim that artists use a reductionist approach is not in keeping with the classic definition of the term (or subsequent ones, for that matter):

A reduction is effected when the experimental laws of the secondary science (and if it has an adequate theory, its theory as well) are shown to be the logical consequences of the theoretical assumptions (inclusive of the coordinating definitions) of the primary science. (Nagel, 1961, p. 352)

Nothing is gained by saying that artists use "reductionism." If we rewrite his statement without it:

Much as a brain scientist can focus on very simple cases of learning and memory to delineate the process of visual perception, so an artist can focus on form, line, color, or light. This allows an artist to move from figuration to abstraction, the absence of figuration.

nothing is lost.

\section{The circularity of Kandel's use of "reductionism."}

The classic illustration of such an explanation is in a speech by a character in Molière's comedy The Imaginary Invalid who intones (the original is on the left, my rough rendering of this ungrammatical mixture of dog Latin and French is on the right):

Mihi a docto doctore.

Domandatur causam et rationem quare

Opium facit dormire.

A quoi respondeo;

Quia est in eo

Vertus dormitiva,

Cujus eat natura

Sensus assoupire.
I asked the learned doctor

For the cause and reason Opium makes one sleep. To which he responded, Because it has in it A dormitive capacity, The nature of which is to Make the senses drowsy.

\footnotetext{
${ }^{4}$ Thirty-two years before Kandel $/$ s book, Vitz and Glimcher 1984 pp. 12, 18-21) advanced the idea of an analyticreductionist "mental attitude or manner of thinking" (p. 12) and claimed that "modernist art begins with the acceptance by artists of the analytic-reductionist approach to painting" (p. 32). Kandel does not cite this book (thoughtfully reviewed by Wertheimer and Werner 1985), even though it may support his claim better than he does.
} 
Kandel is using "reductionism" as Molière uses "dormitive capacity" (or "virtue"). Giving a name is not an explanation 5 The circularity of such illusory explanations is laid out by James (2015):

we observe that sleep follows the intake of opium because it has a dormitive virtue. And why do we believe it has a dormitive virtue? - because sleep follows the intake of opium. And why do we believe sleep follows the intake of opium? — because it has a dormitive virtue. (pp. 491-492)

\section{Kandel's Hegelian impulse.}

But even if the notion of "reductionism" in art were coherent, any attempt to explain a cultural phenomenon by a single principle runs counter to the opinion of major art historians (Kubler. 1962; Summers, 2003, to name just two who have thought deeply about this issue). Gombrich (1999) illustrates:

... art history ... fell back on the Hegelian dogma that changes of style manifest ... a change in will, expressing a different 'world view,' or collective spirit. What secured the spectacular success of this approach, which was taken by such influential writers as William [Wilhelm] Worringer [1881-1965], is the fact that 'expression' is a characteristic shared by all visual configurations. No wonder it suddenly looked as if a master key had been found to the essence of all ages ... (p. 271)

The notion of "reductionism" as used by Kandel also implies a exaggerated belief in continuity. He believes that the drive to "reductionism" began with 19th century artists such as J. M. W. Turner who moved away from the direct representation of appearances in paintings and has persisted - according to Kandel — into the 21 st century with portraits by artists such as Chuck Close.

Unfortunately, this implied continuity undermines our historical understanding by ignoring major artistic upheavals. For instance, according to Dickerman (2012), the birth of abstraction was a difficult one:

Before December 1911, when Kandinsky exhibited Komposition V . . it seems to have been impossible for artists to step away from a long-held tenet of artistic practice: that paintings describe things in a real or imaginary world. (p. 14)

Kandinsky was not taking one small step in the long journey of reduction 7

Another revolution took place in the early 60s. According to Kandel, after the decline of abstract expressionism, there emerged

\footnotetext{
${ }^{5}$ Agreement on this is widespread among philosophers, with one exception: according to Gava (nd pp. 5-6), Peirce (1976 vol. 4, p. 161) thinks that such a process of hypostatic abstraction plays an important role in mathematics, and has a place in the initial stages of an empirical inquiry.

${ }^{6}$ Apparently the Swedish painter Hilma af Klint (1862-1944), whose reputation in the art world began to grow only in 1986, did so in 1906 (Bernitz 2012).

${ }^{7}$ Apologies to Lao Tzu and Neil Armstrong.
} 
... three new traditions, each of which continued to place a major emphasis on deconstruction. The first tradition - a reductionist return to figuration - was pioneered by Katz [who] ... began to use monochromatic backgrounds for his simple, deconstructed portraits. Katz anticipated the second tradition — Pop Art — and ... influenced Roy Lichtenstein, Jasper Johns, and Andy Warhol. Warhol, in turn, influenced Close, who pioneered the third tradition - deconstruction followed by synthesis ... (pp. 163-167)

But this implied continuity does not comport with the facts. Here is Galenson's (2018) account of the shattering events that took place ${ }^{8}$

In the fall of 1962, Sidney Janis presented a group show titled "The New Realism" at his New York gallery, that included paintings by Lichtenstein, Warhol, and other Pop artists. The show drew large crowds, but four Abstract Expressionists, including Rothko, quit Janis' gallery in protest.

... [this] group of younger artists, ... rejected [the] visual approach [of the Abstract Expressionists] in favor of new forms of art based on ideas. (p. 98 9

\section{Abstract art as an apotheosis of art}

Finally, Kandel suggests that forms of art that preceded abstraction relied mostly on bottom-up processing. Furthermore, he argues, abstract art is better than earlier forms of art, because it engages more of the brain; it brings top-down processes to bear in the apprehension of images:

As a result, the visual arts no longer parallel the operations of the brain's bottomup processing of visual information. Abstract art, like Cubism, put an end to what the art critic Carl Einstein called "the laziness or fatigue of vision. Seeing had again become an active process." (Einstein, 1931, p. 107 10,11

Of course, visual systems are designed to give animals useful information about the world in which they live, and for that reason, anomalous inputs - such as abstract art and cubism engender perplexity, which trigger a search for meaning.

But even if abstract art can trigger a search for meaning, it does not follow that representational art does not. On the contrary, there is reason to believe that Elkins (1999) has a point

\footnotetext{
${ }^{8}$ Based on fifty books on Modern Art published between 2000 and 2016.

${ }^{9}$ For more on artistic revolutions, see Clignet (1985).

${ }^{10}$ I have corrected Kandel 's citation, thanks to Prof. Mark Haxthausen's email of July 3, 2019.

${ }^{11}$ Contrary to what Kandel seems to be implying, Einstein was referring to cubism, not abstract art. The original text (in a chapter "Der Kubismus") together with the preceding sentence reads: "Der Kubismus stand nicht beim ersten Anhieb auf den Beinen. Die meisten blieben bei solch vehementem Vormarsch auf der Straße liegen und sind beschäftigt, irgendwelche Nuancen oder zweitklassige Lösungen zu wiederholen. Die Kubisten hatten die Bequemlichkeit oder Ermüdung des Sehens beendet. Schauen war wieder aktiv geworden." Kandel translates "Bequemlichkeit" as "laziness," which is correct, although the more common translations are "comfort," "ease," "convenience." In the present context, an alternative translation might be "passivity." For more on Einstein in English, see Einstein 2004, 2019); Haxthausen (2011).
} 
when he claims that that great art since the Renaissance invariably does so as well, as does post-modernist art.

Consider a disturbing painting by Leon Golub (Figure 1), Many features of this painting

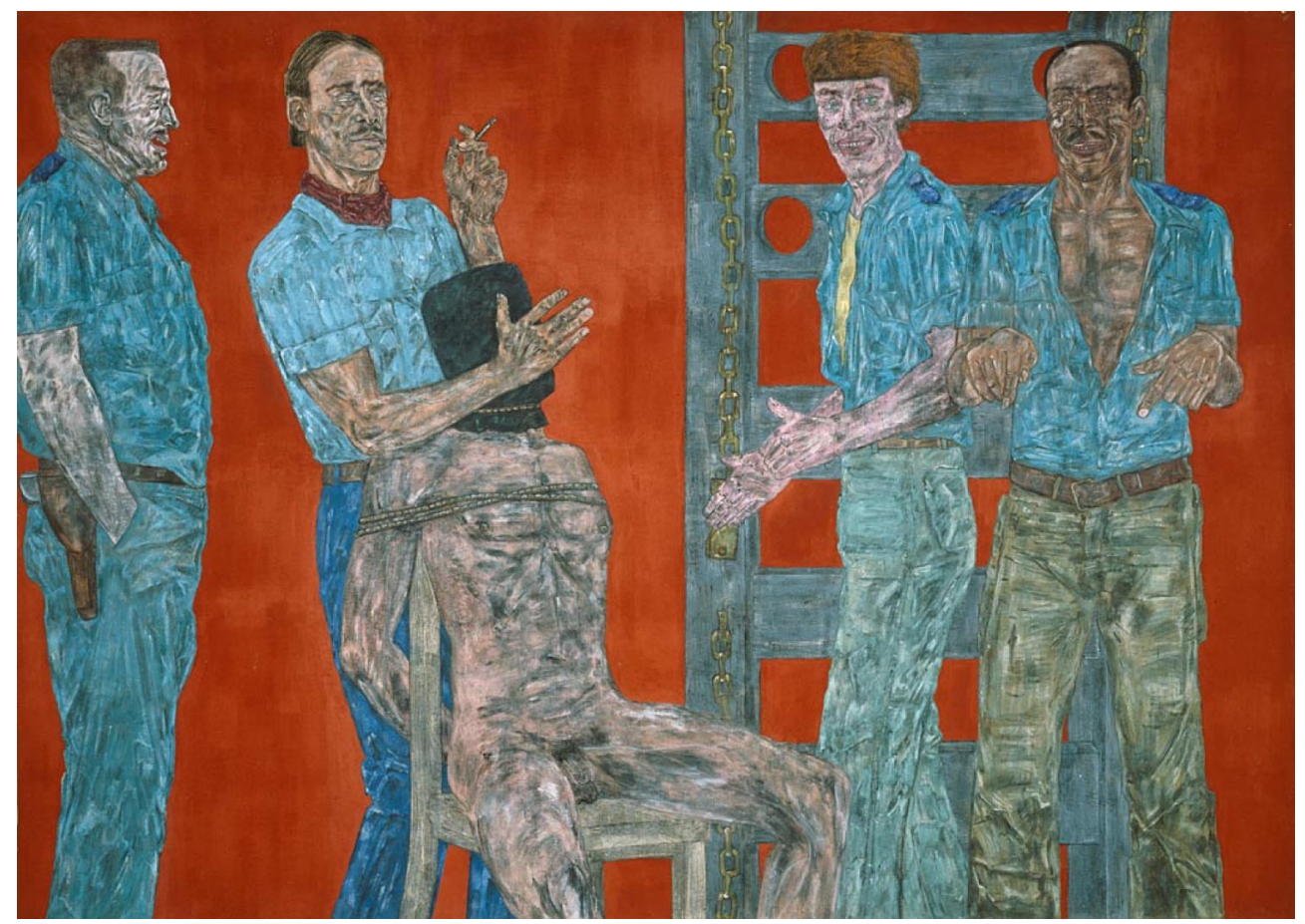

Figure 1 Golub: Interrogation II. 1981. Acrylic on canvas; canvas dimensions: $305 \times 427 \mathrm{~cm}$. Chicago: Art Institute, gift of Society for Contemporary Art 1983.264. (O2019 The Nancy Spero and Leon Golub Foundation for the Arts / Licensed by VAGA at Artists Rights Society (ARS), NY. Photo credit: The Art Institute of Chicago / Art Resource, NY.

puzzle me: the "dirty" mottled texture of the bodies, the absence of information about the events that led up to this scene, my fear for the fate of the prisoner. Soon I notice that the two figures on the right are looking at me, and gesturing. I vacillate between fearing for the prisoner and realizing with dismay that I am not a mere spectator, that I am complicit (for a similar response, see Kuspit, 1986). Is this not an instance of top-down processing?

But Kandel goes even further: he is telling us that abstract art is superior to all others. This idea has been developed in detail by Gablik (1977), who thought that art goes through phases that correspond to Piagetian stages of intellectual development, and that abstract art is its pinnacle, corresponding to Piaget's formal operational stage. Neither this idea, or is any version of the notion of "progress in art," is tenable; it has been debunked several times (Kubovy, 1986, Pariser, 1983). Pariser summarizes :

... some of the principal shortcomings of Gablik's method: There is the questionable utility of applying Piaget's developmental model to a process equally 
governed by personal and social factors ...; there is the questionable parallel between the historical development of art and the evolution of the child's graphic skills; there is the significant cultural chauvinism of Gablik's position. She is a partisan of a certain kind of modern art, and she concludes by "demonstrating scientifically" what must remain her personal preference. (p. 49)

Kubovy reinforces the preceding summary with the following observation:

A similar thesis [to Gablik's] was presented by (Gowans, 1979), apparently formulated without knowledge of Gablik's book. As one who disagrees with this theory, I find some satisfaction in noting a 700-year discrepancy between their chronologies. According to Gowans, the Piagetian stage of formal operations was attained by the Romanesque period (twelfth century), whereas according to Gablik it wasn't attained until late Impressionism (late nineteenth century). (p. 172)

\section{Malady 3: Apply laboratory findings to explain unique works of art}

In his book Consilience, the eminent biologist E. O. Wilson (1998) says about a painting by Mondrian (Figure 2) that the

... spacing of the tree trunks seems intuitively right, the redundancy in the canopy lacework is close to what ... modern EEG monitoring suggests is most arousing to the brain. (p. 241, emphasis mine)

Could Wilson's claim be supported by empirical evidence? No. Because individual cultural products - any particular painting — are difficult to bring into the psychology or neuroscience lab. There are several reasons for this. The first being, What is the question? What hypothesis about this painting would I consider testing in the laboratory? If I took Wilson's words ("most arousing to the brain") literally, I might entertain the hypothesis that the spacing of the tree trunks is - in some sense - optimal. But I would immediately have second thoughts: is there a reason to think that a feature of this painting (such as the spacing of the tree trunks) needs to be optimal for the painting to be worthy of our admiration? None whatsoever.

Of course, one can ask cogent empirical questions about a painting if it is treated as a visual stimulus. For example, Bountis et al. (2017) analyzed the fractal complexity of paintings of trees by Mondrian. They cautiously conclude:

The above analysis suggests that Piet Mondrian, at some point in his life, found it appealing to paint structures with a degree of fractal complexity that may even be described by an approximate dimension of $D=1.75$ (Red Tree) or $D=1.7$ (Farmhouse Tree).

Our observations are valid only for the investigation of two of Mondrian's paintings and only under the limitations of our study and the available resolution of these two paintings. 


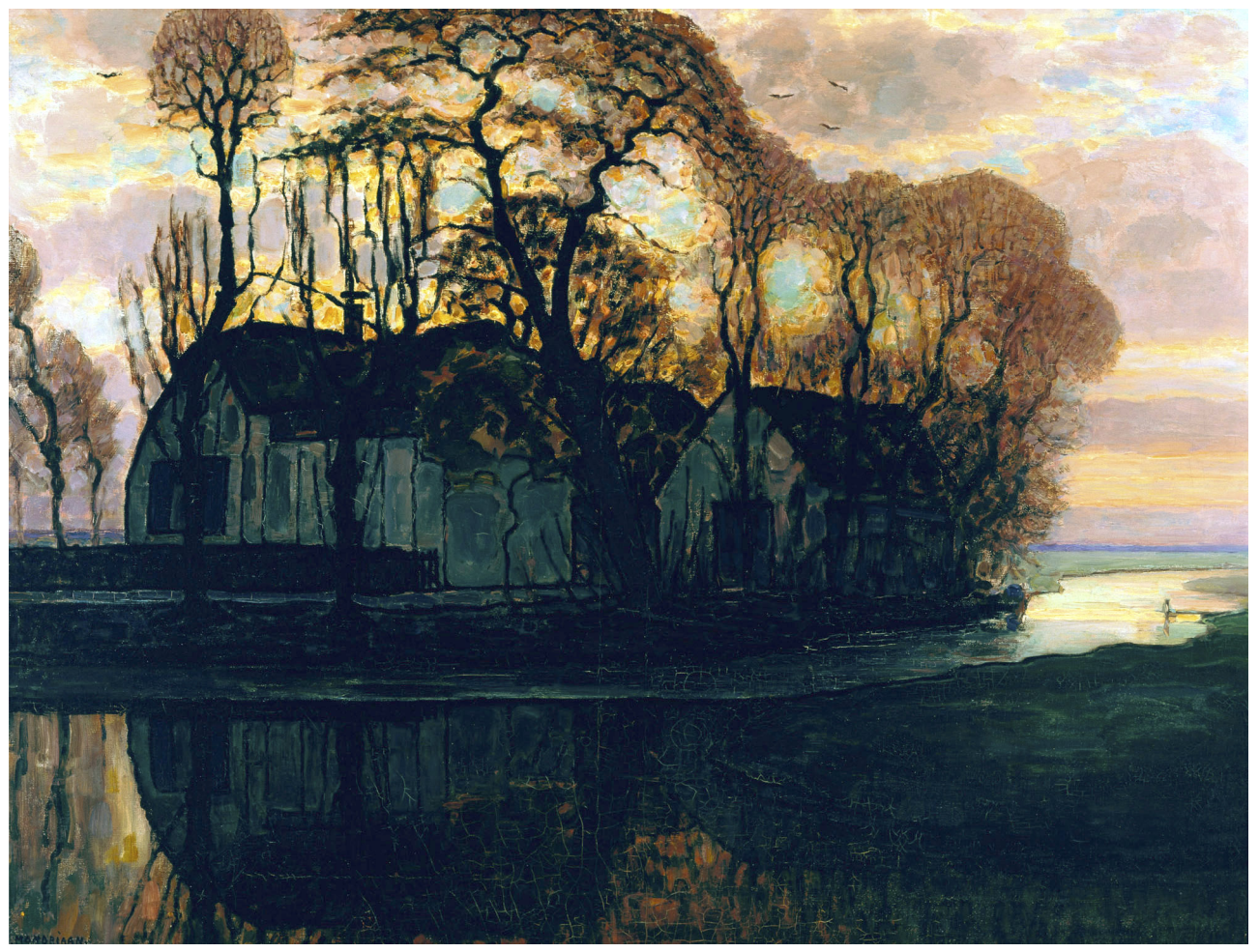

Figure 2 Piet Mondrian, Farm Near Duivendrecht, in the Evening, c. 1916. Oil on canvas; canvas dimensions: $80 \times 106 \mathrm{~cm}$. Dallas Museum of Art, gift of The Edward and Betty Marcus Foundation 1987.359.

Bountis et al. make no claims about optimality or about aesthetic value. Appropriately so, because, as I mentioned earlier (page 5), when we treat works of art primarily as perceptual stimuli, we are missing much of what makes them so valuable to our culture (for a similar view, see ?).

But even supposing I were able to come up with a reasonable empirical hypothesis about this painting, whom would I invite to participate in my study? Should I follow accepted practice in psychological labs and recruit people who are truly naive about what they are about to be shown?

To be sure, I could look for participants who have never been exposed to European art. But that doesn't make much sense, because they never would have had a chance to acquire the extra-pictorial skills and knowledge required to "read" this painting. They do not have the requisite "picturacy" to use Heffernan's 2006 term (coined in analogy with "literacy"). To illustrate, many Italian Renaissance paintings cannot be properly "read" (to use another a term by Heffernan, 2019) unless one refers to the 13th century compendium of stories about the Christian saints and manner of their martyrdom, called the Golden Legend (Jacobus de Voragine, 1993), which was widely known, and was widely used as a source for the 
scenes depicted in art of 14th and 15th century Italy ${ }^{12}$ Nor would they be equipped with the knowledge that underlies sixteen terms (such as "perspective," "ornateness," "variety," and "devotion") that — according to Baxandall (1988, Part III) — " constitute a compact Quattrocento equipment for looking at Quattrocento paintings” (p. 111).

To make my point clear, we look again at the painting by Golub (Figure 1). What kinds of knowledge do I need to appreciate this painting? They are at least three:

1. Understanding the subject of the painting. Aesthetic experiences often depend on the application of historical or culturally prevalent knowledge to the subject-matter of the painting. My response to the painting is informed by my awareness of the brutality of clandestine, semi-official militia in Brazil (1964-1985), Chile (1973-1990), and Argentina (1976-1983).

2. Knowing how other artists treated similar subjects. The experience of this painting is enriched by my ability to contrast it with the way other artists depicted such cruelty (as reviewed by Sontag, 2002), such as Francisco Goya's 82 prints, Los desastres de la guerra (1810-1820) or Sandow Birk's Depravities of War (2007).

3. Knowing about the artist's place in the evolution of styles and techniques. Finally, it is useful to know that Golub used a blade to distress the surface of the painting (Bird, 1997. p. 85), and that this has a precedent in Munch's frequent use of a palette knife to scrape "the canvas so that it looks clawed" (Di Piero, 2010, p. 61).

In the light of these examples - Italian Renaissance painting and Twentieth Century American art - it would make little sense to recruit as subjects people who are not appropriately picturate.

At the other end of the spectrum of potential participants in such an experiment are professors who teach Italian Renaissance art. They would not be of much use to us either; they possess too much picturacy.

In other words, there really is no "Goldilocks" participant in an experiment on a singular, unique work of art, and therefore such experiments cannot be performed, let alone confirm neuroaesthetic hypotheses about singular works of arts.

\section{Malady 4: Use widespread preferences to account for works of art}

In the passage quoted earlier, Wilson also writes:

The arrangement of open space and water nearby are those that recent psychological studies have revealed to be innately among the most attractive out of all such possible arrangements. (p. 241, emphasis mine)

My guess is that he is referring to the work of Orians and Heerwagen (1992), who offer the "savanna hypothesis" - the hypothesis that we have evolved preferences for habitats with features characteristic of a high-quality tropical African savanna,

\footnotetext{
${ }^{12}$ It was key to my reading of Mantegna's The martyrdom of Saint Christopher (Kubovy 1986 Chap. 1).
} 
the environment in which the human lineage is thought to have initially evolved. (p. 555)

The hypothesis - although controversial - enjoys sufficient support (Domínguez-Rodrigo, 2014) to be taken seriously. The question is, what to make of the savanna hypothesis? Should we expect works of art such as the Mondrian in Figure 2 to reflect such an innate preference?

An ironic study of art may give us a clue. During the mid-90s Vitaly Komar and Aleksandr Melamid (Komar and Melamid, 1997), two artists who grew up in the Soviet Union, commissioned professional polling companies to conduct surveys about aesthetic preferences and taste in painting in fourteen countries and the web. Using the data from these surveys, they created two sets of paintings: The Most Wanted paintings, and The Least Wanted (Table 1).

This - they said — was an attempt to discover what a true "people's art" would look like. Of course, paintings created from "most wanted" features, do not create "most wanted" paintings. The variety of paintings on offer from vendors who sell oil paintings by color and size is staggering (taking Fine Art America, as a haphazardly chosen example).That caveat aside, there is striking uniformity among the Most Wanted paintings. And do they resemble environments in which hominins are supposed to have evolved? Domínguez-Rodrigo (2014) mentions Tugen Hills in Kenya as an example. Readers will have to reach their own conclusions.

Most important, though, is to note the similarity between what Komar and Melamid did, and what the savanna hypothesis implies. Each consists of a list of features to which a picture must conform to count as "most wanted" or as support for the savanna hypothesis. They both suggest, but do not prove, innateness of the list of features. But neither says anything about works of art.

These are not the only examples. Some (Palmer and Schloss, 2010) have suggested that innate processes can account for the formation of color preferences: that we like colors associated with what we like (clear skies and clean water) and dislike those associated with what is repellent (feces, rotten food). There is also a body of work showing that broadly shared preferences can also be established in the domain of spatial structure (Palmer et al. 2013).

Such preferences, combined with processing-based theories of preference (Graf and Landwehr, 2015; Reber et al., 2004), and content-based criteria (Ortlieb and Carbon, 2019) collectively constitute what Ortlieb and Carbon call the new aesthetics from below.

But can aesthetics from below illuminate the appeal of the painting by Mondrian? The answer must be no. That a painting exhibits any of the appealing features I have just discussed is neither necessary nor sufficient for understanding it or evaluating it. The only discourse that can help us understand this Mondrian is the discourse of art history, of hermeneutics, of aesthetics from above. I will return to this issue later when I claim that these intellectual endeavors are no less rigorous and exacting than the work of experimental psychologists and neuroscientists.

It would be wise for neuroscientists and psychologists interested in aesthetics to keep in mind the legend of the Chimney of Babel. Once upon a time, two teams were charged with digging a vertical shaft through Mount Aesthetics. The Below team was to drill upward, and 





the Above team was to drill downward. Unfortunately when the project was conceived, two maps had been drawn, indistinguishable except for the location of mountain. To this day it is not known whether the two teams ever met.

\section{Diagnosis: The denial of autonomy}

What are the consequences of these attitudes of neuroscientists toward the arts? Some would argue that no harm is done. Skov and Nadal (2018) may be a bit overenthusiastic, but they have good reasons to worry that some in the humanities (and perhaps in the social sciences) do not take science seriously. Kandel's mission is to help those who cannot keep up with the vast scientific literature, but wish to understand current discoveries:

Thirty years [after an updated edition of Snow's book was published in 1965], John Brockman [1996] advanced Snow's idea in his essay "The Third Culture: Beyond the Scientific Revolution.” Brockman emphasized that the most effective way of bridging the divide would be to encourage scientists to write for the general public in a language that an educated reader can readily understand. This effort is currently under way ... (p. 194)

And Wilson (1998) says:

I admit that the confidence of natural scientists often seems over-weening. Science offers the boldest metaphysics of the age. It is a thoroughly human construct, driven by the faith that if we dream, press to discover, explain, and dream again, thereby plunging repeatedly into new terrain, the world will somehow come clearer and we will grasp the true strangeness of the universe. And the strangeness will all prove to be connected and make sense. (p. 12)

These are all admirable sentiments.

And yet Wilson (1998), for example, believes that the disciplines of the social sciences

... will continue to exist but in radically altered form. In the process the humanities, ranging from philosophy and history to moral reasoning, comparative religion, and interpretation of the arts, will draw closer to the sciences and partly fuse with them. (p. 12)

This confidence in the inevitable absorption of the humanities into science is accompanied by a concern that contemporary scholars in the humanities believe that they

... can proceed without worrying about consilience. About rigor too, it would seem. (p. 207)

If I had to say what Skov and Nadal, Kandel, and Wilson have in common, I would put it as follows: The interpretation of cultural products such as texts and works of art should not be granted an autonomous status with respect to neuroscience or evolutionary theory. I disagree. 


\section{Remedies}

\section{Remedy 1: Respect for autonomy}

The first remedy is to have more respect for the scholarly interpretation of the arts. They need not take my word for it. Indeed, Mantzavinos (2014) has shown how little difference there is between text interpretation (and by extension the interpretation of works of art) and what is typically considered to be scientific discourse:

Text interpretation can be conceptualized and practiced like every other scientific activity: hypotheses are generated and they are tested on the basis of evidence. Generating hypotheses is normally a creative act, which, precisely like the generation of other scientific hypotheses, hardly follows an algorithm: there is no procedure, no specific principle that necessarily leads to the generation of a correct interpretation of a text. Interpretive hypotheses, however, can be evaluated on the basis of evidence, and fitting reconstructions of the nexus of meaning of the text can be differentiated from unfitting reconstructions. Interpretation can be conceptualized as a scientific process of reconstructing nexuses of meaning that can be oriented on the idea of truth ... . (p. 57)

To be sure, there are differences between the interpretive process described by Mantzavinos and the natural sciences. In the natural sciences, we can never exhaust potential sources of evidence to arbitrate between hypotheses. But when it comes to cultural products, the evidence is inherently limited. As a result, some questions may not be answerable (such as, How many children had Lady Macbeth? asked by Knights, 1933). Another limiting factor is that texts and works of art are often ambiguous. For example, Velázquez's Las Meninas, has even been described as "monstrously ambiguous" (Elkins, 1999, p. 123).

And yet, one has only to read some of the vast literature on Las Meninas to find instances of carefully reasoned explications of this monumental painting, very much in accord with the ideas of Mantzavinos (2014, 2016a b c, 2019). I fail to see why we would want such interesting, thought-provoking analyses of Velázquez's painting to undergo the sort of radical alteration in form predicted by Wilson, nor how they could possibly "draw closer to the sciences and partly fuse with them."

Perhaps the key issue here is an excessively broad notion of reduction held by neuroscientists vis-à-vis psychology. In recent years it has become clear that even when some reduction is possible, the secondary science must retain its autonomy from the primary science. For example, Lombardi and Ferreira Ruiz (2019) convincingly argue for the autonomy of chemistry from physics:

not only the theoretical virtues of chemistry, but primarily its pragmatic virtues are the factors that, although not proving independence, play a decisive role in the arguments for the autonomy of the chemical domain. (p. 143)

Likewise, they should recognize the autonomy of psychology from neuroscience, so clearly argued by Sharp and Miller (2019). 
And if we accept the autonomy of psychology from neuroscience, we surely must also accept the autonomy of the interpretation of cultural products from psychology. In other words, the interpretation of cultural products is recursively autonomous from neuroscience. This suggests that neuroaestheticians should rein in the scope of their ambition.

In the introduction to this article, I observed that although scientists said that they wanted to build a bridge between the sciences and the rest of human culture, they were confident that non-scientists would have to gravitate toward them. They never proposed a program that had scientists think more like scholars in the humanities. My analysis of four examples from the literature of neuroaesthetics is consistent with this view.

\section{Remedy 2: Draw questions from art history and tolerate ambiguity}

My book, The Psychology of Perspective and Renaissance Art, was triggered by noticing an inconsistency between an entry in one of Leonardo da Vinci's notebooks and his Last Supper. In his notebooks he writes:

If you wish to represent a thing near, which should produce the effect of natural things, it is impossible for your perspective not to appear false, by reason of all the illusory appearances and errors in proportion of which the existence may be assumed in a mediocre work, unless whoever is looking at this perspective finds himself surveying it from the exact distance, elevation, angle of vision or point at which you were situated to make this perspective [i.e., the center of projection (COP)]. (Leonardo da Vinci, 2005, p. 121)

But then he proceeds to paint the Last Supper, whose COP is roughly three times above the eye-height of an average person.

This is the art-historical puzzle that was the initial impetus for the book. On my way to proposing a solution to the puzzle, I introduced the idea of the robustness of perspective, subsequently summarized by Pagel (2017):

... the principal goal of a perspective image of a scene is considered to be the provision of a stimulus that is functionally equivalent to the one provided by the original scene when viewed monocularly from ... [the COP]. Viewed monocularly from the COP, the perspective image and original scene will (ideally) project the same pattern of light onto the observer's retina ... . When viewed outside the COP, different light patterns are projected. However, when looking at pictures [binocularly], a change of viewing position is usually not associated with substantial perceptual effects. The perception of linear-perspective images is, in a manner of speaking, robust regarding viewing position. (p. 2)

The solution I proposed to the puzzle involves the following conjecture. By the time Leonardo painted the Last Supper, he may have understood the robustness of perspective. And yet, he didn't trust it do accomplish the desired goal of minimizing the perceptual effects of viewing the fresco from a viewing position other than the COP. So he designed the perspective 
of the virtual room in which he imagined the last supper could have taken place, so that it would align with pre-existing architectural features of the refectory, but only if the viewer's eye was at the unattainable location of the COP. And so he provided a clue for the viewer's visual system to infer the location of the COP, thus giving it the wherewithal to compensate for being at the "wrong" viewing position.

That this conjecture has spawned experiments testing the compensation hypothesis (see Pagel, 2017, for an overview) is evidence of the fruitfulness of the approach I took. Although the book drew upon empirical research in psychology, it does not — could not have — the rigor of experimental research.

It is this sort of tolerance for ambiguity, conjecture, and speculation that the neuro- or cognitive aesthetician must be willing to accept, with no assurance that it could ever attain the standards of rigor required of an experimental research program.

\section{Remedy 3: Draw questions from aesthetic theory}

But is such a retreat from rigor inevitable, or can neuroscientists and psychologists benefit from what is valuable in the thinking of artists and scholars in the humanities without giving up the rigor of their method and theories? Sometimes. Here is an example of a study that does just that.

In 1841, in response to a query about the meanings of some of his Songs without Words, Felix Mendelssohn-Bartholdy (1864) wrote

For my part I believe that words do not suffice for such a purpose, and if I found they did suffice, then I certainly would compose no more music. People often complain that music is so ambiguous, that what they are to think about it always seems so doubtful, whereas every one understands words ; with me it is exactly the reverse; not merely with regard to entire sentences, but also to individual words; these, too, seem to me so ambiguous, so vague, so unintelligible when compared with genuine music, which fills the soul with a thousand things better than words. (p. 276)

Heinrich Heine once said (Peter, 1977, p. 343, attributed without source) "When words leave off, music begins." The philosopher Peter Kivy (2009) writes

"Absolute music," then, as defined, is pure instrumental music without text, title, program, dramatic setting, or any other extra-musical apparatus. It is music, as defined, without representational, narrative, semantic or other extra-musical content. (p. 197)

and in Kivy (1991) he describes it as a

quasi-syntactical structure of sound understandable solely in musical terms and having no semantic or representational content, no meaning, making reference to nothing beyond itself. (p. 202) 
In other words, we are considering music that is not linked by the composer to a narrative (such as Hector Berlioz's Symphonie Fantastique or to a description (such as Modest Mussorgsky's Pictures at an Exhibition). Can such music convey specific semantic concepts?

To answer the question, Koelsch et al. (2004) used a technique called semantic priming (Meyer and Schvaneveldt, 1971). This is a phenomenon whereby a word, called the target, is more readily processed if it is preceded by a semantically related word, called the prime (e.g., BREAD [prime] - BUTTER [target]) than if it is preceded by an unrelated prime (e.g., BREAD [prime] - DOCTOR [target]). This advantage is most often detected using reaction time. But in this study, Koelsch et al. used EEG-based event-related potentials (ERPs), which show (Kutas and Hillyard, 1980) a larger negative peak at about 300 to 500 ms (denoted N400) after an unrelated target than after a related one, indicating the "reprocessing" of semantically anomalous information (for a review, Rossell et al., 2003).

In the experiment (which I'm simplifying), targets were German words, such as WIDENESS, or NARROWNESS. Primes were either sentences or musical excerpts. Examples of priming sentences: THE GAZE WANDERS INTO THE DISTANCE for wideness, and THE SHACKLES ALLOW LITTLE MOVEMENT for narrowness. Examples of musical excerpts: intervals covering a large range of pitches for wideness, and dissonant intervals covering a small range of pitches for narrowness. Target words elicited an N400 when they were primed either by semantically unrelated sentences or by semantically unrelated musical excerpts.

So now, thanks to an elegant experiment that combines psychology and neuroscience, we have the sketch of an empirical answer to a long-standing question about the nature of music. It brings us one step closer to a theory of musical semantics, such as advanced by Rohrmeier et al. (2015) or Schlenker 2018).

\section{Envoi}

In 1946 Jorge Luis Borges wrote a miniature story, "On rigor in science." In it he quotes a supposed seventeenth century explorer, Suárez Miranda, who visited an empire in which "the Schools of Cartographers built a Map of the Empire, that was of the Size of the Empire, and which coincided point for point with it" (translated by Doval, 2017). Those Cartographers, who were overly ambitious, ended up creating a map that cannot function as a map. So do those neuroscientists, whose approaches suffer from the ailments discussed here, end up creating explanations that cannot explain human cultural products. 


\section{References}

11988 [1] Baxandall, M. (1988). Painting and experience in Fifteenth Century Italy: A primer in the social history of pictorial style. Oxford University Press, Oxford, UK, 2nd edition.

2012 [2] Bernitz, A. M. (2012). Hilma af Klint and the new art of seeing. Avant-Garde Critical Studies, 28:587-597.

11997 [3] Bird, J. (1997). Infvitabile Fatum: Leon Golub's history painting. The Oxford Art Journal, 20(1):81-94.

¿2007 [4] Birk, S. (2007). The depravities of war. Huipress \& Grand Centeral Press, Makawo, Maui, HI \& Santa Ana, CA, US.

12017 [5] Bountis, T., Fokas, A. S., and Psarakis, E. Z. (2017). Fractal analysis of tree paintings by Piet Mondrian (1872-1944). International Journal of Arts and Technology, 10(1):27-42.

11996 [6] Brockman, J. (1996). Third culture: Beyond the scientific revolution. Simon and Schuster, New York, NY, US.

E1985 [7] Clignet, R. (1985). The structure of artistic revolutions.

2012 [8] Clothier, P. (2012). Slow looking: The art of looking at art. Toad Rampant Books, Los Angeles, CA, US.

2010 [9] Di Piero, W. S. (2010). On Edvard Munch. The Yale Review, 98(1):58-64.

2012 [10] Dickerman, L., editor (2012). Inventing abstraction, 1910-1925: How a radical idea changed modern art. Museum of Modern Art, New York, NY, US.

2014 [11] Domínguez-Rodrigo, M. (2014). Is the "savanna hypothesis" a dead concept for explaining the emergence of the earliest hominins? Current Anthropology, 55(1):59-81.

2017 [12] Doval, D. (2017). Borges' 'On rigor in science' - A new annotated translation. https: //medium.com/@diego./borges-on-rigor-in-science-ba3cd98a40af, last checked October $21,2019$.

1931 [13] Einstein, C. (1931). Die Kunst des XX Jahrhunderts. Propyläen Verlag, Berlin, DE, 3rd edition.

2004 [14] Einstein, C. (2004). Notes on cubism. October, 107:158-168. Translated and introduced by Charles W. Haxthausen.

2019 [15] Einstein, C. (2019). A mythology of forms: Selected writings on art. University of Chicago Press, Chicago, IL, US. Translated and introduced by Charles W. Haxthausen.

1999 [16] Elkins, J. (1999). Why are our pictures puzzles? On the modern origins of pictorial complexity. Routledge, New York, NY, US. 
2001 [17] Elkins, J. (2001). Pictures and tears: A history of people who have cried in front of paintings. Routledge, New York, NY, US, kindle edition.

2019 [18] Fine Art America. Oil original artwork.

2013 [19] Fumagalli, R. (2013). The futile search for true utility. Economics and Philosophy, 29(3):325347.

1977 [20] Gablik, S. (1977). Progress in art. Rizzoli, New York, NY, US.

2018 [21] Galenson, D. W. (2018). Pricing revolution: From abstract expressionism to pop art. Research in Economics, 72(1):86-100.

2019 [22] Gava, G. (n.d.). Prescission. In Bergman, M. and Queiroz, J., editors, The commens Encyclopedia: The digital encyclopedia of Peirce studies. http://www.commens.org/encyclopedia/a rticle/gava-gabriele-prescission, last checked July 14, 2019.

1973 [23] Geertz, C. (1973). Thick description: Toward an intepretive theory of culture, pages 310-323. Basic Books, New York, NY, US.

1975 [24] Giedymin, J. (1975). Antipositivism in contemporary philosophy of social science and humanities. The British Journal for the Philosophy of Science, 26(4):275-301.

1999 [25] Gombrich, E. H. (1999). The uses of images: Studies in the social function of art and visual communication. Phaidon, London, UK.

1979 [26] Gowans, A. (1979). Child art as an instrument for studying history: The case for an 'ontogeny repeats phylogeny' paradigm in universal history. Art History, 2(3):247-274.

2015 [27] Graf, L. K. M. and Landwehr, J. R. (2015). A dual-process perspective on fluency-based aesthetics. Personality and Social Psychology Review, 19(4):395-410.

2002 [28] Guillory, J. (2002). The Sokal affair and the history of criticism. Critical Inquiry, 28(2):470508.

2018 [29] Gutting, G. and Oksala, J. (2018). Michel Foucault. In Zalta, E. N., editor, The Stanford Encyclopedia of Philosophy. Metaphysics Research Lab, Stanford University, Palo Alto, CA, US, summer 2018 edition.

2011 [30] Haxthausen, C. W. (2011). Carl Einstein, Daniel-Henry Kahnweiler, Cubism, and the visual brain. Nonsite.org, (2).

2006 [31] Heffernan, J. A. W. (2006). Cultivating picturacy: Visual art and verbal interventions. Baylor University Press, Waco, TX, US.

2019 [32] Heffernan, J. A. W. (2019). Reading pictures. PMLA, 134(1):18-34.

2014 [33] Huettel, S. A. (2014). Neuroeconomics. In Gazzaniga, M. S. and Mangun, G. R., editors, The cognitive neurosciences, pages 1063-1070. MIT Press, Cambridge, MA, US, 5th edition. 
1993 [34] Jacobus de Voragine (1993). The golden legend: Readings on the saints. Princeton University Press, Princeton, NJ, US.

2015 [35] James, E. (2015). Beyond the magical thinking behind the principal principle. Philosophy, 90(3):479-503.

2005 [36] Kahneman, D. and Riis, J. (2005). Living, and thinking about it: Two perspectives on life. In Huppert, F., Baylis, N., and Keverne, B., editors, The science of well-being, chapter 11, pages 285-304. Oxford University Press, Oxford, UK.

2018 [37] Kahnt, T. (2018). A decade of decoding reward-related fMRI signals and where we go from here. NeuroImage, 180:324-333.

2016 [38] Kandel, E. R. (2016). Reductionism in art and brain science: Bridging the two cultures. Columbia, New York, NY, US.

1991 [39] Kivy, P. (1991). Music alone: Philosophical reflections on the purely musical experience. Cornell University Press, Ithaca, NY, US.

2009 [40] Kivy, P. (2009). Antithetical arts: On the ancient quarrel between literature and music. Oxford University Press, Oxford, UK.

1933 [41] Knights, L. (1933). How many children had Lady Macbeth? Gordon Fraser, the Minority Press, Cambridge, UK.

2004 [42] Koelsch, S., Kasper, E., Sammler, D., Schulze, K., Gunter, T., and Friederici, A. D. (2004). Music, language and meaning: brain signatures of semantic processing. Nature Neuroscience, 7(3):302-307.

1997 [43] Komar, V. and Melamid, A. (1997). Painting by numbers: Komar and Melamid's scientific guide to art. Farrar Straus \& Giroux, New York, NY US. See survey and pictures online at http://awp.diaart.org/km/.

1962 [44] Kubler, G. (1962). The shape of time: Remarks on the history of things. Yale University Press, New Haven, CT, US.

1986 [45] Kubovy, M. (1986). The psychology of perspective and Renaissance art. Cambridge University Press, New York, NY, US.

1986 [46] Kuspit, D. (1986). The existential/activist painter: The example of Leon Golub. Rutgers University Press, New Brunswick, NJ, US.

1980 [47] Kutas, M. and Hillyard, S. (1980). Reading senseless sentences: Brain potentials reflect semantic incongruity. Science, 207(4427):203-205.

2008 [48] Landreth, A. and Bickle, J. (2008). Neuroeconomics, neurophysiology and the common currency hypothesis. Economics and Philosophy, 24(3):419-429. 
2005 [49] Leonardo da Vinci (2005). Leonardo's notebooks: Writing and art of the grand master. Black Dog \& Leventhal Publishers, New York, NY US.

2012 [50] Levy, D. J. and Glimcher, P. W. (2012). The root of all value: A neural common currency for choice. Current Opinion in Neurobiology, 22:1027-1038.

2019 [51] Lombardi, O. and Ferreira Ruiz, M. J. (2019). Distinguishing between inter-domain and intra-domain emergence. Foundations of Science, 24(1):133-151.

1965 [52] Luce, R. D. and Suppes, P. (1965). Preference, utility, and subjective probability. In Luce, R., Bush, R., and Galanter, E., editors, Handbook of mathematical psychology, volume 3, pages 249-410. Wiley, New York, NY US.

2013 [53] Mannella, F., Gurney, K., and Baldassarre, G. (2013). The nucleus accumbens as a nexus between values and goals in goal-directed behavior: A review and a new hypothesis. Frontiers in Behavioral Neuroscience, 7.

2014 [54] Mantzavinos, C. (2014). Text interpretation as a scientific activity. Journal for General Philosophy of Science, 45(S1):45-58.

16b [55] Mantzavinos, C. (2016a). Explanatory pluralism. Cambridge University Press, Cambridge, UK.

$16 a$ [56] Mantzavinos, C. (2016b). Hermeneutics. In Zalta, E. N., editor, The Stanford Encyclopedia of Philosophy. Metaphysics Research Lab, Stanford University, winter 2016 edition.

2016 [57] Mantzavinos, C. (2016c). The nature of science. A dialogue. Synthese, 196(3):775-793.

2019 [58] Mantzavinos, C. (2019). A dialogue on understanding. Philosophy of the Social Sciences.

1864 [59] Mendelssohn-Bartholdy, F. (1864). Letters of Felix Mendelssohn Bartholdy from 1833 to 1847. Longman, Green, Longman, Roberts \& Green, London, UK.

1971 [60] Meyer, D. E. and Schvaneveldt, R. W. (1971). Facilitation in recognizing pairs of words: Evidence of a dependence between retrieval operations. Journal of Experimental Psychology, 90(2):227-234.

1961 [61] Nagel, E. (1961). The structure of science: Problems in the logic of scientific explanation. Routledge \& Kegan Paul, London.

1992 [62] Orians, G. H. and Heerwagen, J. H. (1992). Evolved responses to landscapes. In Barkow, J. H., Cosmides, L., and Tooby, J., editors, The adapted mind: Evolutionary psychology and the generation of culture, pages 555-579. Oxford University Press, New York, NY, US.

19b [63] Ortlieb, S. A. and Carbon, C.-C. (2019). Kitsch and perception: Towards a new 'aesthetic from below'. Art \& Perception, 7:1-26.

2017 [64] Pagel, R. (2017). The duality of picture perception and the robustness of perspective. Art \& Perception, 5(3):233-261. 
2010 [65] Palmer, S. E. and Schloss, K. B. (2010). An ecological valence theory of human color preference. Proceedings of the National Academy of Sciences, 107(19):8877-8882.

2013 [66] Palmer, S. E., Schloss, K. B., and Sammartino, J. (2013). Visual aesthetics and human preference. Annual Review of Psychology, 64(1):77-107.

1983 [67] Pariser, D. (1983). The pitfalls of progress: A review and discussion of Gablik's Progress in Art. Visual Arts Research, 9(1):41-54.

1976 [68] Peirce, C. S. (1976). The new elements of mathematics. Mouton, The Hague, Netherlands.

1994 [69] Perkins, D. N. (1994). The intelligent eye: Learning to think by looking at art. Occasional Paper 4, The Getty Center for Education in the Arts, Santa Monica, CA.

1977 [70] Peter, L. J. (1977). Peter's quotations: Ideas for our time. Morrow, New York, NY US.

1999 [71] Ramachandran, V. S. and Hirstein, W. (1999). The science of art: A neurological theory of aesthetic experience. Journal of Consciousness Studies, 6(6-7):15-51.

2004 [72] Reber, R., Schwarz, N., and Winkielman, P. (2004). Processing fluency and aesthetic pleasure: Is beauty in the perceiver's processing experience? Personality and Social Psychology Review, 8(4):364-382.

2017 [73] Reed, A. (2017). Slow art: The experience of looking, sacred images to James Turrell. University of California Press, Oakland, CA, US.

114a [74] Reyna, V. F. and Huettel, S. A. (2014). Reward, representation, and impulsivity: A theoretical framework for the neuroscience of risky decision making. In Reyna, V. F. and Huettel, S. A., editors, The neuroscience of risky decision making, pages 11-42. American Psychological Association, Washington, DC, US.

2015 [75] Rohrmeier, M., Zuidema, W., Wiggins, G. A., and Scharff, C. (2015). Principles of structure building in music, language and animal song. Philosophical Transactions of the Royal Society B: Biological Sciences, 370(1664).

2003 [76] Rossell, S. L., Price, C. J., and Nobre, A. C. (2003). The anatomy and time course of semantic priming investigated by fMRI and ERPs. Neuropsychologia, 41(5):550-564.

2009 [77] Ryle, G. (2009). The concept of mind. Routledge, Milton Park, Abdingdon, Oxon, UK.

2018 [78] Schlenker, P. (2018). Prolegomena to music semantics. Review of Philosophy and Psychology, 10(1):35-111.

1996 [79] Scott, J. (1996). Postmodern gravity deconstructed, slyly. The New York Times.

2019 [80] Sharp, P. B. and Miller, G. A. (2019). Reduction and autonomy in psychology and neuroscience: A call for pragmatism. Journal of Theoretical and Philosophical Psychology, 39(1):18-31. 
2018 [81] Skov, M. and Nadal, M. (2018). Art is not special: An assault on the last lines of defense against the naturalization of the human mind. Reviews in the Neurosciences, 29(6):699-702.

1965 [82] Snow, C. P. (1965). The Two Cultures: And a second Look. Cambridge University Press, Cambridge, UK.

2013 [83] Snow, C. P. (2013). The two cultures and the scientific revolution. Martino Fine Books, Eastford, CT, US.

1998 [84] Sokal, A. and Bricmont, J. (1998). Fashionable nonsense: Postmodern intellectuals' abuse of science. Picador, New York, NY, US.

$996 a$ [85] Sokal, A. D. (1996a). A physicist experiments with cultural studies. Lingua Franca, 6:62-64.

1996 [86] Sokal, A. D. (1996b). Transgressing the boundaries: Towards a transformative hermeneutics of quantum gravity. Social Text, No. 46/47:217-252.

2003 [87] Solso, R. L. (2003). The psychology of art and the evolution of the conscious brain. MIT Press, Cambridge, MA, US.

2002 [88] Sontag, S. (2002). Looking at war: Photography's view of devastation and death. The New Yorker, pages 82-98.

2003 [89] Summers, D. (2003). Real spaces: World art history and the rise of Western Modernism. Phaidon, London, UK.

2015 [90] Tan, K., Dong, S., Liu, X., Chen, W., Wang, Y., Oldroyd, B. P., and Latty, T. (2015). Phantom alternatives influence food preferences in the eastern honeybee Apis cerana. Journal of Animal Ecology, 84:509-517.

2017 [91] Tishman, S. (2017). Slow looking: The art and practice of learning through observation. Routledge, New York, NY, US.

1972 [92] Tversky, A. (1972). Elimination by aspects: A theory of choice. Psychological Review, 79(4):281-299.

1992 [93] Tversky, A. and Shafir, E. (1992). Choice under conflict: The dynamics of deferred decision. Psychological Science, 3(6):358-361.

1984 [94] Vitz, P. C. and Glimcher, A. B. (1984). Modern art and modern science: The parallel analysis of vision. Praeger, New York, NY US.

1985 [95] Wertheimer, M. and Werner, J. S. (1985). Review of Modern art and modern science: The parallel analysis of vision by paul c. vitz and arnold b. glimcher. The American Journal of Psychology, 98(2):328-331.

1998 [96] Wilson, E. O. (1998). Consilience: The unity of knowledge. Alfred A. Knopf, New York, NY, US. 
2015 [97] Xu, Z. (2015). Uncertain multi-attribute decision making: Methods and applications. Springer, Heidelberg, DE.

2005 [98] Zaidel, D. W. (2005). Neuropsychology of art: Neurological, cognitive and evolutionary perspectives. Psychology Press, London, UK.

1999 [99] Zeki, S. (1999a). Art and the brain. Journal of Consciousness Studies, 6(6-7):76-96.

99a [100] Zeki, S. (1999b). Inner vision: An exploration of art and the brain. Oxford University Press, Oxford, UK. 